\title{
Situational Affect and Temperament: Implications for Sibling Caregiving
}

\author{
Brenda L. Volling*, Carla Herrera ${ }^{\dagger}$ and Michelle P. Poris ${ }^{\ddagger}$ \\ University of Michigan, Department of Psychology, USA
}

The caregiving behaviour of 60 preschool-age children $(M=50$ months) toward their 16-month-old younger siblings was observed during a brief separation from their parents. Sibling caregiving was more strongly associated with parent ratings of both the older siblings' and toddlers' temperament than with the younger siblings' distress exhibited during the separation. The older siblings' social fear was positively related to providing care, whereas their temperamental activity level was negatively related to caregiving. Younger siblings' temperamental anger and soothability were positively associated with receiving care from an older sibling. Relations with temperament were independent of both children's distress levels during the separation, and in several instances, dispositional affective measures (i.e. temperament) made stronger contributions to the prediction of sibling caregiving than did situational distress. Copyright (C) 2004 John Wiley \& Sons, Ltd.

Key words: sibling; caregiving; temperament

\section{SITUATIONAL AFFECT AND TEMPERAMENT: IMPLICATIONS FOR SIBLING CAREGIVING}

Providing care to a distressed person is a sophisticated prosocial act that, remarkably, has been documented even in very young children (Dunn and Munn, 1986). Recently, researchers have outlined several emotion-related child characteristics that predict children's caregiving behaviour, including emotion understanding (Garner et al., 1994), emotional expression (Fabes et al., 1994; Farver and Branstetter, 1994), and emotion regulation (Eisenberg et al., 1992a). Few investigators have examined the role that dispositional affect or temperament may play in young children's caregiving, even though it is theorized to play a prominent role in children's early self-regulation and conscience development (Kochanska, 1994, 1995). The aim of the current study was to examine how preschool children's situational and dispositional emotional expression influenced individual differences in sibling caregiving.

\footnotetext{
*Correspondence to: Brenda L. Volling, Department of Psychology, 525 E. University, University of Michigan, Ann Arbor, MI 48109-1109, USA. E-mail: volling@umich.edu

${ }^{\dagger}$ Carla Herrera is now at Public/Private Ventures in Philadelphia, PA.

${ }^{\ddagger}$ Michelle Poris is now at Just Kid Inc. in Stamford, CT.
} 
One significant influence on children's caregiving behaviour is the emotional distress the child experiences in the caregiving context. Although some affective arousal is necessary in order for the child to empathize with another, children who are overaroused are less likely to focus on the needs of another and more likely to attempt to regulate their own negative affective state (Feshbach, 1979; Eisenberg et al., 1996a; Roberts and Strayer, 1996). Temperamental differences in the child's emotional disposition may similarly influence children's prosocial behaviour and caregiving behaviour (Eisenberg et al., 1996b; Farver and Branstetter, 1994). Social fear, or inhibition, is of particular relevance to the study of caregiving because of its centrality in theories of internalization and moral conduct (see Kochanska, 1993). Socially fearful, school-age children were found to provide less verbal comforting to a baby whose cries were heard over a loudspeaker (Eisenberg et al., 1996b). Temperamental effects can also be seen when examining the child's negative emotionality or anger, as well as their activity level. Children higher in negative emotionality and those who are temperamentally difficult exhibited less prosocial or socially appropriate behaviour than children low on negativity (Eisenberg et al., 1995, 1996b; Farver and Branstetter, 1994). In addition, preschool and school-age siblings with higher activity levels exhibited more agonistic behaviour toward their siblings and were involved in more sibling conflict than children who exhibited lower activity levels (e.g. Stoneman and Brody, 1993).

The younger siblings' affective behaviour or distress in the caregiving situation, as well as their dispositional temperament, may also contribute to the older siblings' caregiving behaviour. Older siblings whose younger siblings are more prone to anger may provide more caregiving because they have been exposed to the toddlers' distressing emotions in the home (Eisenberg et al., 1992b; Garner et al., 1994) and may have witnessed specific parental caregiving strategies to deal with toddler distress. Similarly, older siblings may need to use less comforting with an easily soothed younger sibling. The distress level of the person needing care is also important in determining caregiving behaviour (Dunn and Munn, 1986; Garner et al., 1994), suggesting that the toddler sibling's distress in the caregiving context (i.e. situational affect) should also be related to the older sibling's caregiving. More toddler distress may emotionally arouse an older sibling and lead to more sibling caregiving.

\section{METHOD}

\section{Participants}

Sixty-two preschool children, their mothers, fathers and younger toddler siblings participated. Families were recruited from local birth announcements, day care centres and the university subject pool. Parents were married and mostly white (93\%). Families had a median income of $\$ 60,000$. Fathers were, on average, 36 years of age and had completed 17 years of education, whereas mothers were, on average, 33 years old and had completed 16 years of education. One family terminated participation before the sibling visit and one family had separated by this time; thus, the final sample included 60 families with 20 sister pairs, 14 brother pairs, 10 older brother-younger sister pairs and 16 older sister-younger brother pairs. Older siblings were 50 months old, on average, and most had only one younger sibling $(n=45)$. Their younger siblings were 16 months old at the time of the sibling assessment. In this paper, the older of the two siblings will be 
referred to as the 'older sibling' and the younger sibling will be referred to as the 'toddler sibling'.

\section{Procedure}

The data were drawn from assessments made at three different time points, when the toddler was 12-, 13-, and 16 months old. Data for the present report were obtained during a 3-min parent separation session at the 16-month visit and from parent reports of the children's temperament completed at the 12/13 month visits.

\section{Sibling and Toddler Temperament}

To assess temperament, both parents completed the Toddler Behavior Assessment Questionnaire (TBAQ; Goldsmith, 1996) for the older sibling and the Infant Behavior Questionnaire (IBQ; Rothbart, 1981) for the toddler. Only four of the TBAQ scales were used: activity level, social fear, pleasure, and anger proneness. The IBQ has 6 scales, but only those scales relevant to the toddler's distress to limitations/anger and soothability were retained. Internal consistency was greater than 0.70 for all scales. To yield more valid measures of temperament, mothers' and fathers' scores, with one exception, were correlated and then averaged to yield one composite for each child temperament scale (Rushton et al., 1984). Only mothers' reports were used to assess toddler soothability given the nonsignificant correlation between mother and father reports.

\section{Observational Measures of Sibling Caregiving}

At the 16-month laboratory visit, both parents left the room for a 3-min separation period during which the older sibling's caregiving behaviour was observed. Each videotaped separation episode was later coded for distress on the part of both children and older sibling caregiving behaviour. Coders were trained to at least $80 \%$ agreement on caregiving and distress codes before actual coding began. To calculate interrater reliability, two coders separately coded 19 (33\%) of the separations.

The following caregiving behaviours were coded for the older sibling using 10-s interval sampling: physical comforting, $(\kappa=0.89)$, verbal comforting $(\kappa=0.89)$, and redirecting attention $(\kappa=0.92)$. Physical and verbal comforting were summed and expressed as a proportion of the intervals the older sibling provided comforting given the total number of intervals in which the toddler was distressed. Redirecting attention was also expressed as a proportion score. In an effort to assess the repertoire of strategies used by the older sibling, children received a score (0-3) for whether they used one or more of the three caregiving strategies. The child who enacts numerous caregiving behaviours when comforting a distressed other may have a greater repertoire of caregiving scripts available.

Given that some older siblings might attempt to 'escape' as a means of coping with the toddler's or their own distress, a decision rule was made whereupon the separation session was terminated by the experimenter if the older sibling opened the door to leave and/or seek their parents. The length of the separation episode before termination was used as an indicator of the older siblings' avoidance of the distressing situation and consisted of the proportion of 10-s separation intervals that the older sibling remained with the toddler. The 
duration (in seconds) of both the older siblings' and toddlers' distress throughout the episode (due to the parents' departure) was coded (e.g. fussing, standing at door with sad face, whimpering). Any distress that was caused by the sibling (e.g. the older sibling pushes a younger sibling who starts to cry) was not included in this duration measure. During their parents' absence, 42 of the 58 toddlers who separated from their parents $(72 \%)$ became distressed. This distress lasted an average of $22.8 \mathrm{~s}$. Because the length of the separation episodes varied, a proportion score for toddler distress was calculated by noting the number of seconds the toddler was distressed divided by the total duration of the separation. Eight older siblings became distressed during the separation (14\%), which lasted an average of $17.25 \mathrm{~s}$. Because distress was fairly infrequent for the older sibling, this measure was dichotomized.

Initial analyses showed that all caregiving variables occurred relatively infrequently and had skewed distributions. Thus, scores for comforting, redirecting attention, and multiple care strategies were dichotomized based on the presence (1) or absence (0) of the behaviour in question. The length of the separation before curtailing was also dichotomized, but in this case, older siblings able to withstand the entire separation were coded 0 and those who left and had the session terminated were coded 1.

\section{RESULTS}

Point-biserial coefficients were conducted to determine whether the older siblings' age was associated with the caregiving measures. Older preschool siblings were more likely to redirect the attention of their toddler siblings than were younger preschool siblings $\left(r_{\mathrm{pb}}=0.38, t(40)=-2.90, p<0.01\right)$. The older siblings' age was added as a covariate in the analyses that follow. To examine whether the older siblings' caregiving behaviour differed for dyads of different gender compositions, each of the four dichotomous caregiving measures was cross-tabulated with the gender composition of the sibling dyad (e.g. brothersister, sister-brother). None of these analyses was significant.

Phi coefficients calculated to examine relations among the four caregiving measures revealed relations between the older siblings' use of multiple caregiving strategies and their comforting behaviour $(r \phi=0.82, p<0.001)$, as well as with redirecting attention $(r \phi=0.53, p<0.001)$. Curtailing the separation episode was negatively associated with comforting $(r \phi=-0.33, p<0.05)$, indicating that those older siblings curtailing the separation were less likely to provide comfort for their toddler siblings.

One-way ANCOVAs conducted with the dichotomized measure of older sibling situational distress used as the between subjects factor, older sibling age as a covariate, and the older siblings' temperament as the dependent variables revealed no significant effects. Correlations were conducted between toddler temperament scales and the duration of the toddler's situational distress and revealed no significant results. To determine whether older sibling and toddler situational distress were related, one final ANCOVA was conducted with toddler situational distress as the dependent variable and the dichotomous distress variable for the older sibling as the between subjects factor (older sibling age as a covariate). No association was found between the older and younger siblings' situational distress.

Phi-coefficients were calculated to examine relations between the older siblings' distress during the separation and whether they performed any of the 
caregiving behaviours. None of these analyses was significant. Point-biserial coefficients examining the associations between the older siblings' caregiving and the extent of toddler situational distress were all non-significant.

In an effort to determine whether the older siblings' or toddlers' temperament differed based on whether the older sibling provided care, ANCOVAs were conducted where the dichotomous caregiving measures were used as between subjects factors, and the four scales of older siblings' temperament were the dependent variables, controlling for older sibling age. These analyses revealed a comfort group main effect for the older siblings' activity level, $F(1,41)=5.52$, $p<0.05$. Older siblings providing comfort to their toddler siblings had lower activity level scores $(M=3.72)$ than those who provided no comfort $(M=3.98)$. There was also a significant group effect when examining those children who did or did not use multiple caregiving strategies for the older siblings' activity level, $F(1,41)=5.97, p<0.05$, and social fear, $F(1,41)=3.88, p=0.056$. Older siblings using multiple care strategies were less active $\left(M_{s}=3.73\right.$ versus 4.01$)$ and more socially fearful $\left(M_{s}=3.71\right.$ versus 3.22$)$ than those who did not. Finally, there was a significant curtailing group effect for the older siblings' anger, $F(1,57)=4.06$, $p<0.05$. Older siblings who curtailed the separation by leaving the room were rated by parents as being more temperamentally angry $(M=3.87)$ than those who did not curtail the separation $(M=3.46)$.

ANCOVAs examining toddler temperament and the four older sibling caregiving measures, revealed a significant group effect for the multiple caregiving groups for the toddlers' anger, $F(1,41)=4.01, p<0.05$, and soothability, $F(1,41)=4.99, p<0.05$. Toddlers had higher anger and soothability scores in the group of older siblings using multiple care strategies $\left(M_{\mathrm{s}}=4.20\right.$ and 5.24 for distress and soothability, respectively) than in the group of older siblings who did not use one or more caregiving strategies $\left(M_{\mathrm{s}}=3.82\right.$ and 4.66). A significant comfort group main effect was also found for toddler soothability, $F(1,41)=4.83$, $p<0.05$. Toddlers' had higher soothability scores in the group receiving physical and verbal comforting from older siblings than those not receiving such comfort $\left(M_{\mathrm{s}}=5.29\right.$ and 4.72$)$.

\section{Multiple Prediction of Older Sibling's Caregiving}

Logistic regression analyses were conducted to assess the unique contributions of temperament and situational distress, for both the older and younger siblings, on the older siblings' caregiving. Each logistic regression model consisted of three steps. Older siblings' age was entered in the first step, while the older siblings' and toddlers' situational distress during the separation were entered in the second step. Older sibling or toddler temperament variables were then added in a third step. To minimize the number of independent variables used in predicting these outcomes, separate logistic regression models were examined using one of the temperament variables in the final step of each model. Temperament variables were chosen based on significant associations found in the univariate analyses. A total of seven logistic regression models were analysed-four using older sibling temperament and three using toddler temperament as predictors of the older siblings' caregiving. Results of the logistic regression analyses using older sibling temperament are presented in Table 1 and those for toddler temperament are in Table 2.

When the older siblings' social fear was entered in the third step, the overall model was significant, $\chi^{2}(4 d f)=17.60, p<0.001$, indicating that one or more of 
Table 1. Logistic regression analyses predicting sibling caregiving from older sibling's age, situational distress and temperament

\begin{tabular}{|c|c|c|c|c|c|c|c|}
\hline $\begin{array}{l}\text { Caregiving } \\
\text { measure }\end{array}$ & Step & Predictor variable & $\Delta \chi^{2}$ & $b$ & SE & Wald & $\mathrm{e}^{b}$ \\
\hline $\begin{array}{l}\text { Multiple } \\
\text { caregiving } \\
\text { strategies }\end{array}$ & $\begin{array}{l}1 \\
2\end{array}$ & $\begin{array}{l}\text { Older sibling age } \\
\text { Toddler distress } \\
\text { Older sibling } \\
\text { distress } \\
\text { Older sibling } \\
\text { social fear } \\
\text { Constant }\end{array}$ & $\begin{array}{l}\chi^{2}(1)=2.74 \\
\chi^{2}(2)=6.83^{*} \\
\chi^{2}(1)=8.04^{* *}\end{array}$ & $\begin{array}{r}0.04 \\
-3.29^{*} \\
-2.49 \\
1.42^{*} \\
-4.47\end{array}$ & $\begin{array}{l}0.03 \\
1.40 \\
1.47 \\
\\
0.57\end{array}$ & $\begin{array}{l}1.23 \\
5.49 \\
2.87\end{array}$ & $\begin{array}{l}1.04 \\
0.04 \\
0.08\end{array}$ \\
\hline $\begin{array}{l}\text { Multiple } \\
\text { caregiving } \\
\text { strategies }\end{array}$ & $\begin{array}{l}1 \\
2\end{array}$ & $\begin{array}{l}\text { Older sibling age } \\
\text { Toddler distress } \\
\text { Older sibling } \\
\text { distress } \\
\text { Older sibling } \\
\text { activity level } \\
\text { Constant }\end{array}$ & $\begin{array}{l}\chi^{2}(1)=2.74 \\
\chi^{2}(2)=6.83^{*}\end{array}$ & $\begin{array}{l}-0.01 \\
-2.15 \\
-2.97^{*} \\
-3.46^{*} \\
15.57\end{array}$ & $\begin{array}{l}0.04 \\
1.29 \\
1.53 \\
\\
1.54\end{array}$ & $\begin{array}{l}0.13 \\
2.75 \\
3.76\end{array}$ & $\begin{array}{l}0.99 \\
0.12 \\
0.05\end{array}$ \\
\hline Comforting & $\begin{array}{l}1 \\
2\end{array}$ & $\begin{array}{l}\text { Older sibling age } \\
\text { Toddler distress } \\
\text { Older sibling } \\
\text { distress } \\
\text { Older sibling } \\
\text { activity level } \\
\text { Constant }\end{array}$ & $\begin{array}{l}\chi^{2}(1)=0.01 \\
\chi^{2}(2)=3.19 \\
\chi^{2}(1)=6.33^{* *}\end{array}$ & $\begin{array}{l}-0.06 \\
-1.07 \\
-2.02 \\
-2.73^{*} \\
13.40\end{array}$ & $\begin{array}{l}0.04 \\
1.25 \\
1.31 \\
\\
1.28\end{array}$ & $\begin{array}{l}2.33 \\
0.74 \\
2.40\end{array}$ & $\begin{array}{l}0.95 \\
0.34 \\
0.13\end{array}$ \\
\hline Curtailing & $\begin{array}{l}1 \\
2\end{array}$ & $\begin{array}{l}\text { Older sibling age } \\
\text { Toddler distress } \\
\text { Older sibling } \\
\text { distress } \\
\text { Older sibling } \\
\text { anger } \\
\text { Constant }\end{array}$ & $\begin{array}{l}\chi^{2}(1)=0.04 \\
\chi^{2}(2)=1.22\end{array}$ & $\begin{array}{r}0.02 \\
-0.59 \\
1.12\end{array}$ & $\begin{array}{l}0.03 \\
0.88 \\
1.19\end{array}$ & $\begin{array}{l}0.43 \\
0.45 \\
0.89\end{array}$ & $\begin{array}{l}1.02 \\
0.55 \\
3.06\end{array}$ \\
\hline
\end{tabular}

${ }^{*} p<0.05,{ }^{* *} p<0.01$.

Note. All predictor coefficients $(b)$ reflect values when variables were entered at Step 3 in the logistic regression analysis. $\mathrm{e}^{b}=$ odds ratio; the increase in odds of membership for a one unit increase in the predictor while controlling for other predictors in the model.

the predictor coefficients in the model was significantly different from zero. The $\Delta \chi^{2}$ at each step indicates that variables entered in Steps 2 and 3 made a significant independent contribution to the prediction of the multiple caregiving strategies used by older siblings (see Table 1). In this case, both the toddlers' situational distress and the older siblings' social fear were significant predictors. In the case of the older siblings' social fear, the odds ratio $\left(\mathrm{e}^{b}\right)$ indicated that for every unit increase in the older siblings' social fear, there was a 4.15 times greater odds of providing care to the younger sibling (see Table 1). The low odds ratio for the toddlers' situational distress indicates that the likelihood was nearly zero that the toddlers' distress during the separation increased the odds that the 
Table 2. Logistic regression analyses predicting older sibling caregiving from older sibling age, situational affect and toddler temperament

\begin{tabular}{lcllrrrr}
\hline $\begin{array}{l}\text { Caregiving } \\
\text { measure }\end{array}$ & Step & Predictor variable & $\Delta \chi^{2}$ & $b$ & SE & Wald & $\mathrm{e}^{b}$ \\
\hline Multiple & 1 & Older sibling age & $\chi^{2}(1)=2.74$ & 0.02 & 0.03 & 0.62 & 1.03 \\
caregiving & 2 & $\begin{array}{l}\text { Toddler distress } \\
\text { strategies }\end{array}$ & $\chi^{2}(2)=6.83^{*}$ & $-2.91^{*}$ & 1.36 & 4.59 & 0.06 \\
& \multirow{2}{*}{$\begin{array}{l}\text { Older sibling } \\
\text { distress }\end{array}$} & & -2.27 & 1.29 & 3.10 & 0.10 \\
& $\begin{array}{l}\text { Toddler anger } \\
\text { Constant }\end{array}$ & $\chi^{2}(1)=5.75^{*}$ & $1.55^{*}$ & 0.72 & 4.69 & 4.71 \\
& & -5.45 & & & \\
\hline
\end{tabular}

${ }^{*} p<0.05,{ }^{* *} p<0.01$.

Note. All predictor coefficients $(b)$ reflect values when variables were entered at Step 3 in the logistic regression analysis. $\mathrm{e}^{b}=$ odds ratio; the increase in odds of membership for a one unit increase in the predictor while controlling for other predictors in the model.

older sibling would attempt to use one or more caregiving strategies. Thus, the older siblings' dispositional social fear, not the toddlers' situational distress, increased the odds that the older sibling would provide care to the toddler.

When examining the older siblings' activity level as the measure of temperament in Step 3, this model was also significant, $\chi^{2}(4 \mathrm{df})=17.43$, $p<0.01$. Both the older siblings' distress and their activity level were significant predictors of whether the older sibling used multiple caregiving strategies (see Table 1). Specifically, the negative value of the predictor coefficients suggested that the predicted odds of using multiple care strategies decreased as both the older siblings' distress increased and their activity level increased. Also, the nearzero odds ratios for these variables indicate that it was highly unlikely for an active or distressed older sibling to use one or more care strategies with the toddler.

A third logistic regression model used the older siblings' activity level as the measure of temperament to predict the older siblings' comforting behaviour. Again, the likelihood ratio statistic for the overall model was significant, $\chi^{2}$ ( $4 \mathrm{df})=9.52, p<0.05$, and revealed that only the older siblings' activity level was a significant predictor of the older siblings' comforting behaviour (see Table 1). In this case, the predicted odds of the older sibling providing comfort to their younger sibling decreased as the older siblings' activity level increased. Again, the odds ratio of 0.07 underscores the low likelihood of a highly active older sibling providing comfort to a distressed toddler.

The older siblings' anger was examined as a unique predictor of whether or not the separation had been curtailed because the older sibling left the room. The overall likelihood statistic for the model was not significant in this case, $\chi^{2}$ $(4 \mathrm{df})=5.84, p=0.21$, but the $\Delta \chi^{2}$ statistic for Step 3 did indicate a significant odds increase with the addition of the older siblings' anger (see Table 1). Furthermore, the predictor coefficient for the older siblings' anger was significant in the final model when all variables had been entered, indicating the odds of the separation being curtailed because the older sibling left the room increased 3.33 times for every unit increase in the older siblings' anger.

Logistic regression analyses were also conducted to explore the unique contribution of toddler temperament to older sibling caregiving after controlling 
for older sibling age and both the older and toddler siblings' distress during the separation (see Table 2). Toddlers' anger was used to predict whether or not the older sibling tried multiple caregiving strategies during the separation. A significant likelihood ratio statistic for the overall model was found, $\chi^{2}$ $(4 \mathrm{df})=15.31, p<0.01$, and both the toddlers' situational distress and their dispositional anger were significant predictors of the older siblings' use of multiple caregiving strategies (see Table 2). The near-zero odds ratio highlights the low likelihood of an older sibling using more than one caregiving behaviour with a distressed toddler. In addition, for every one unit increase in the toddlers' dispositional anger, there was a corresponding 4.71 increase in the odds of the older sibling using one or more care strategies during the separation. None of the other models tested using toddler soothability revealed significant findings.

\section{DISCUSSION}

The current study provides preliminary insights into the contributions of temperament to children's caregiving behaviour. Importantly, older sibling and toddler temperament accounted for variance in the prediction of the older siblings' caregiving above and beyond that accounted for by situational measures of distress. The older siblings' situational distress was rarely associated with their caregiving behaviour, whereas their temperamental affect made unique contributions to caregiving in several cases. For example, socially fearful older siblings were more likely to try multiple caregiving strategies to ease the distress of their toddler sibling. Others have also found that social fear is related to children's moral development and prosocial behaviour (e.g. Kochanska, 1995; Eisenberg et al., 1996b), which suggests that these children may be more sensitive to the negative affective cues of others and thus, more likely to experience the anxiety, discomfort and guilt that may promote more caregiving efforts.

Those older siblings choosing to leave the room and curtail the separation were also those children rated by their parents as high on temperamental anger, suggesting that anger-prone older siblings were less likely to tolerate the separation and more likely to seek escape. Fabes and Eisenberg (1992) have found that young preschool children used a number of different means to cope with interpersonal anger and observed socially competent preschool boys coping in a more direct manner with peer conflicts eliciting anger (e.g. actively resisting the child who provoked the conflict or expressing disapproval of the child initiating conflict). Socially competent and popular boys were less likely to seek adult assistance when angered, suggesting that perhaps the anger-prone older siblings in the current research who sought out adult assistance were not able to cope effectively with the separation paradigm or their toddler siblings' distress. On the other hand, Volling (2001) found that 4-year-old older siblings were less likely to engage in sibling conflict and express hostility toward a younger sibling if they had sought adult assistance during a separation paradigm similar to the one used in the current research. Thus, seeking adult assistance in a situation that might lead to conflict could be regarded as a highly effective means of coping, particularly for a child prone to hostile outbursts or angry confrontations.

In no instance did the older siblings' dispositional pleasure or positive affect relate to caregiving behaviour. This is surprising given the importance of shared positive affect in sibling relationships for children's emotional understanding and perspective-taking abilities (Dunn et al., 1991). Happy dispositions did not play as much of a role in determining whether or not an older sibling provided 
care to a younger sibling as did the older siblings' negative affect (e.g. anger, fear) and their activity level, which some have found increases sibling conflict (Munn and Dunn, 1989). Although the positive affect or sociable disposition of an older sibling may be important in determining whether the older sibling initiates play with a younger toddler or maintains a pleasurable exchange of cooperative play (Dunn and Munn, 1986; Youngblade and Dunn, 1995), other more negative emotional states (e.g. fear, guilt) may serve as the basis of sibling caregiving, which is similar to arguments advanced on the development of children's conscience (Kochanska, 1993). Children expressing sympathy reactions (i.e. other-oriented concern) are much more likely to engage in prosocial behaviour than those exhibiting personal distress reactions in response to another's distress (Fabes and Eisenberg, 1992). Children experiencing personal distress in response to another's distress may also provide caregiving, but often it may be motivated by the desire to terminate their own distress by ending the distress of the other. In any event, sibling caregiving in response to a younger siblings' distress may be more a function of the empathy or personal distress a child feels than whether or not they are prone to experience positive affect.

The toddlers' temperament and distress also emerged as significant contributors to the older siblings' caregiving. Temperamentally angry and soothable toddlers both elicited the use of multiple care strategies from their older siblings, suggesting that different temperamental characteristics of the distressed other may elicit similar caregiving behaviour, but perhaps for different reasons. Using multiple caregiving strategies to comfort a distressed and angry toddler may be an attempt to assuage one's own personal distress, whereas such strategy use with a soothable toddler may reflect mutually responsive and positive sibling interactions, in general. Future research needs to consider how the temperament and affective expression of both the provider and recipient of care interact to predict caregiving behaviour.

Unfortunately, parents' behaviours before and after the separation from their children were not assessed in the current work, but they no doubt play an important role in shaping how older siblings respond to a distressed toddler. Further, parental behaviour may also differ depending on the older siblings' and toddlers' temperaments. Parents may be more likely to ask the older sibling explicitly to comfort the younger sibling in cases where the toddler is more likely to become distressed (i.e. has a more 'fussy' temperament) or be less inclined to ask a highly active and agitated older sibling to care for the toddler because any involvement might erupt into sibling conflict. Broader issues such as parenting style, attachment relationships, and parental differential treatment of the siblings are other socialization factors that may have an impact on the sibling relationship, prosocial behaviour, and sibling caregiving (Volling, 2001; Volling and Belsky, 1992) and should be considered as potential moderating factors in future examinations of temperament and sibling caregiving.

\section{ACKNOWLEDGEMENTS}

This research was funded by a Rackham faculty grant and a faculty grant from the Office of the Vice President of Research at the University of Michigan. This work was conducted while the second and third authors were supported by NSF graduate fellowships and the second author was supported by a Rackham Merit Fellowship. We are grateful to John Kaufmann, Joelle Larsen, Nancy McElwain, and Paul Notaro for their assistance with data collection and to John Heintzman, 
Kari Horenstein, Laura Nemiroff, Karla Rojas, and Robert San Juan for their contributions to coding. Portions of this research were presented at the Biennial Meeting of the Society for Research in Child Development in Washington D.C., 1997.

\section{REFERENCES}

Dunn J, Brown J, Slomkowski C, Tesla C, Youngblade L. 1991. Young children's understanding of other people's feelings and beliefs: Individual differences and their antecedents. Child Development 62: 1352-1366.

Dunn J, Munn P. 1986. Siblings and the development of prosocial behaviour. International Journal of Behavioral Development 9: 265-284.

Eisenberg N, Bernzweig J, Fabes RA. 1992a. Coping and vicarious emotional responding. In Stress and Coping in Infancy and Childhood, Field TM, McCabe PM, Schneiderman N (eds). Lawrence Erlbaum Associates: Hillsdale, NJ; 101-117.

Eisenberg N, Fabes RA, Carlo G, Karbon M. 1992b. Emotional responsivity to others: behavioral correlates and socialization antecedents. In New Directions for Child Development No. 55: Emotion and its Regulation in Early Development, Eisenberg N, Fabes RA (eds). Jossey-Bass: San Francisco; 57-73.

Eisenberg N, Fabes RA, Karbon M, Murphy BC, Carlo G, Wosinski M. 1996a. Relations of school children's comforting behaviour to empathy-related reactions and shyness. Social Development 5: 330-351.

Eisenberg N, Fabes RA, Karbon M, Murphy BC, Wosinski M, Polazzi L, Carlo G, Juhnke C. 1996b. The relations of children's dispositional prosocial behaviour to emotionality, regulation, and social functioning. Child Development 67: 974-992.

Eisenberg N, Fabes RA, Murphy B, Maszk P, Smith M, Karbon M. 1995. The role of emotionality and regulation in children's social functioning: a longitudinal study. Child Development 66: 1360-1384.

Fabes RA, Eisenberg N. 1992. Young children's coping with interpersonal anger. Child Development 63: 116-128.

Fabes RA, Eisenberg N, Karbon M, Troyer D, Switzer G. 1994. The relations of children's emotion regulation to their vicarious emotional responses and comforting behaviours. Child Development 65: 1678-1693.

Farver JM, Branstetter WH. 1994. Preschoolers' prosocial responses to their peers' distress. Developmental Psychology 30: 334-341.

Feshbach N. 1979. Studies of empathic behaviour in children. In Progress in Experimental Personality Research, Maher B (ed.), vol. 8. Academic Press: New York; 1-45.

Garner PW, Jones DC, Palmer DJ. 1994. Social cognitive correlates of preschool children's sibling caregiving behaviour. Developmental Psychology 30: 905-911.

Goldsmith HH. 1996. Studying temperament via construction of the toddler behaviour assessment questionnaire. Child Development 67: 218-235.

Kochanska G. 1993. Toward a synthesis of parental socialization and child temperament in early development of conscience. Child Development 64: 325-347.

Kochanska G. 1994. Beyond cognition: expanding the search for the early roots of internalization and conscience. Developmental Psychology 30: 20-22.

Kochanska G. 1995. Children's temperament, mother's discipline, and security of attachment: multiple pathways to emerging internalization. Child Development 66: 597-615.

Munn P, Dunn J. 1989. Temperament and the developing relationship between siblings. International Journal of Behavioral Development 12: 433-451.

Roberts W, Strayer J. 1996. Empathy, emotional expressiveness, and prosocial behaviour. Child Development 67: 449-470.

Rothbart MK. 1981. Measurement of temperament in infancy. Child Development 52: 569-578.

Rushton J, Brainerd C, Pressley M. 1984. Behavioral development and construct validation: The principle of aggregation. Psychological Bulletin 94: 18-38. 
Stoneman Z, Brody GH. 1993. Sibling temperaments, conflict, warmth, and role asymmetry. Child Development 64: 1786-1800.

Volling BL. 2001. Early attachment relationships as predictors of preschool children's emotion regulation with a distressed sibling. Early Education and Development 12: 185-207.

Volling BL, Belsky J. 1992. The contribution of mother-child and father-child relationships to the quality of sibling interaction: a longitudinal study. Child Development 63: 1209-1222.

Youngblade L, Dunn J. 1995. Individual differences in young children's pretend play with mother and sibling: links to relationships and understanding of other people's feelings and beliefs. Child Development 66: 1472-1492. 